\title{
Del cuerpo a la imagen. Lógica de las imágenes y proceso figurativo en el cine de Philippe Garrel
}

\author{
Gorputzetik irudira. Irudien logika eta prozesu \\ figuratiboa Philippe Garrelen zineman
}

\section{From body to image. The logic of images and figurative process in the cinema of Philippe Garrel}

\author{
Arnau Vilaró i Moncasí ${ }^{1}$
}

\section{zer}

Vol. 21 - Núm. 41

ISSN: $1137-1102$

e-ISSN: $1989-631 \mathrm{X}$

DOI: $10.1387 /$ zer. 16404

pp. 93-109.

2016

Recibido el 21 de febrero de 2016, aceptado el 2 de junio de 2016.

\section{Resumen}

Gilles Deleuze considera a Philippe Garrel como el cineasta que culmina con un pensamiento figurativo en el cine. El siguiente artículo aborda los principios de esta tesis tomando el vínculo que los cuerpos adquieren en el montaje fílmico. Para ello, propone el análisis estético de los dos períodos en los que se divide la obra del cineasta: uno de experimental, en el que destaca la presencia y la participación de su amante Nico, y otro de narrativo, donde el cineasta filma la relación que el nacimiento del hijo establece con el amor pasado e irrecuperable de Nico.

Palabras clave: Cine, historia del cine, proceso cinematográfico, análisis textual, estética del film.

\section{Laburpena}

Gilles Deleuzek gorena jo zuen zineman pentsamendu figuratiboa erabiliz, Philippe Garrelen esanetan. Artikulu honetan, tesi horren printzipioak jorratzen ditu, gorputzek film-muntaketan lortzen duten loturari helduz. Horretarako, zinemagilearen obra bereizteko erabiltzen diren bi aldien azterketa estetikoa egiten du: bata, azterketa esperimentala; bestea, narraziozkoa. Lehenengoan, zinemagilearen maitale Nicoren presentzia eta parte-hartzea nabarmentzen da, eta bigarrenean, zinemagileak haren semearen jaiotzak Nicorekiko iraganeko maitasun berreskuraezinarekin ezartzen duen harremana filmatzen du.

\footnotetext{
${ }^{1}$ Instituto de Investigaciones Estéticas de la Universidad Nacional Autónoma de México, arnau.vilaro@gmail.com
} 
Gako-hitzak: Zinema, zinemaren historia, prozesu zinematografikoa, testu-analisia, filmaren estetika.

\begin{abstract}
Gilles Deleuze deems Philippe Garrel to be the filmmaker who has best expressed cinematographic thought departing from body narrative. The article that follows discusses the principles of this thesis from the link existing among bodies and film editing. To best understand Garrel's proposal, the text proposes an esthetic analysis of both periods into which the work of this filmmaker is divided: the experimental where the presence and participation of his lover Nico and the narrative one where Garrel films the link existing between the birth of his son and the forgone and unretrievable love of Nico.
\end{abstract}

Keywords: Cinema, film history, filmmaking, textual analysis, film aesthetics. 


\section{Introducción}

El primer cortometraje de Philippe Garrel, Les enfants desaccordés (1964), anuncia los motivos principales de la generación de cineastas franceses protagonizados por el mismo Garrel junto con Jean Eustache, Maurice Pialat, Chantal Akerman o Jacques Doillon: el inconformismo político y la rebelión social, la profunda desafección de la vida cotidiana y, por consiguiente, la indeleble separación del individuo con su mundo. Separación de la sociedad, en el caso de Les enfants desaccordés, pero también del padre (Anémone, 1968), del hijo y la pareja (Le révélateur, 1968), de la Tierra y el discurso bíblico (Le lit de la vierge, 1969).

Fabrice Revault d'Allones se refirió a la "separación" como el término que mejor definía el cine de Garrel: "Si existe un tema garreliano, si fuera necesario anunciarlo con una sola palabra, diría que es la separación. [...] Formalmente, el plano garreliano lucha contra la desaparición de los seres queridos, procura retenerlos, mirarlos ${ }^{2}$ el máximo tiempo posible, y, fatalmente, filmar el carácter inexorable, irremediable, de su desaparición. De su separación con la mirada del cineasta, del espectador". (Païni, 1988: 29). En el mismo sentido, Garrel declaraba a Thomas Lescure: "En el origen de mis películas hay siempre un conflicto, algo doloroso y la separación, para mí, es la escena primitiva" (Garrel y Lescure, 1992: 22).

Las figuras propias de un cuerpo separado del mundo al que pertenece parecen estar en el centro creativo de la generación nacida con el espíritu del Mayo del 68 y de las secuelas de la Guerra de Argelia. En sus filmes protagonistas, los héroes se enfrentan a la asunción de la derrota y el rechazo y son habituales los rostros empapados de lágrimas, que resisten al dolor y cantan al amor antes de morir. Imágenes del sollozo, del ahogo, de la asfixia. Françoise Lebrun en La maman et la putain (Eustache, 1973), Marlène Jobert en Nous ne vieillirons pas ensemble (Pialat, 1972), Dominique Laffin en La femme qui pleure (Doillon, 1979) o Chantal Akerman filmándose a sí misma en su habitación, en Je tu il elle (1974). Las imágenes manifiestan la visibilidad del sufrimiento, mientras que a su vez ambicionan huir del cierre, o permanecer en el mismo cierre para afirmarse como sistemas fundados en la repetición y la circularidad de las acciones, los gestos y las posturas.

¿Cómo la estética de los filmes responde a los problemas visibles en el plano narrativo? ¿Cómo la separación opera también en este sentido? ¿Existe una lógica de las imágenes y por consiguiente un sistema generalizado después de la Nouvelle Vague? ¿Cómo el cine y el proyecto figurativo de Philippe Garrel contribuye a ello y ocupa un lugar dentro de esta lógica?

El siguiente artículo pretende dar respuestas a estas preguntas. Para ello, parte de las observaciones que hizo Gilles Deleuze en torno al cineasta en el segundo volumen de su ontología del cine, La imagen-tiempo (1985), donde el filósofo francés consideró Garrel como el autor que culmina con un cine pensado desde el cuerpo. Empero, antes de revisar las tesis de Deleuze y examinar la hipótesis según la cual la separación se convierte en el principio que funda este cine de cuerpos, veamos cuál fue la tradición que el cine de Garrel y sus coetáneos tomaron en relación con los planteamientos de la Nouvelle Vague, pues, como dejó escrito Domènec Font a

2 Mirar, en francés, regarder. El autor escribe re-garder para referirse al mismo tiempo a mirar y a guardar. 
partir de un conocido texto de Serge Daney ${ }^{3}$, los del 68 "atravesaron su tiempo con dificultades, no sólo por la condición coalescente de su propio entorno sino por sus dependencias hacia los padres que estaban todavía en activo" (Font, 2012: 427).

\section{Philippe Garrel y el cine del 68}

\subsection{De la Nouvelle Vague a la Post-Nouvelle Vague. O de la búsqueda de lo visible a la construcción de la mirada}

Numerosos estudios han abordado el conocido período de la Nouvelle Vague protagonizado por Jean-Luc Godard, Claude Chabrol, Jacques Rivette, Eric Rohmer y François Truffaut ${ }^{4}$. Sin embargo, y pese a la existencia de excelentes trabajos sobre los cineastas del 68 [(Magny, 1992), (Philippon, 1986), (Prédal, 2003) o (Garrel, Lescure, 1992)], cabe destacar una ausencia de estudios que traten el conjunto del movimiento de cineastas posteriores. Sin duda, como avanzábamos al final de la introducción, algo lo explica: Pialat, Eustache, Akerman, Doillon o Garrel, todos ellos aparecieron al mismo tiempo que algunas de las obras más destacadas de la misma Nouvelle Vague, como Ma nuit chez Maud (Rohmer, 1969), Que la bête meure (Claude Chabrol, 1969), L'amour fou (Rivette, 1969) o Tout va bien (Godard, 1972), siendo la Nouvelle Vague tanto su terreno de inspiración y aprendizaje como una losa para la creación, o como escribe David Vasse, "un horizonte siempre luminoso y molesto a la vez" (Vasse, 2008: 27). En su reciente obra sobre el conjunto de estos cineastas, María Velasco (2012) propone cuatro características propias de los enfants perdus de la Post-Nouvelle Vague: la virtud de la pobreza, la verdad de lo real, el diario íntimo y la venganza del mismo cine. Estos rasgos ponen de manifiesto una continuidad al mismo tiempo que culminan con las ideas de sus predecesores: el cambio en el sistema de producción de los filmes, el planteamiento ontológico del cine y la conciencia del vínculo con lo real, la teoría del autor y la deconstrucción de los códigos y convenciones sobre la puesta en escena creadas por el cine institucional.

En la misma línea, el plano estético informa de otra relación. En otro trabajo analizamos los elementos que determinan un universo estético particular en el cine francés de la Nouvelle Vague. Por un lado, constatábamos la creación de un cine preocupado por el fenómeno de lo visible, cuya reflexión arrancaba al situar la figura del Otro en el centro de la motivación creadora de los cineastas. Por otro lado, si, de acuerdo con las palabras de Jean-Marc Lalanne, la Nouvelle Vague se convirtió en un método a seguir para los cineastas posteriores (Lalanne, 2002: 8081 ), esto fue porque puso en crisis la relación narrativa para mantener la relación - o más bien su búsqueda- desde la figuración, en términos de montaje y de puesta en escena (Vilaró, 2016).

\footnotetext{
3 Nos referimos al texto "Le crû et le cuit (État du cinéma français, 1980)", publicado en La rampe. Cahier critique 1970-1982. París: Cahiers du Cinéma - Gallimard, pp. 189-196.

4 Destacan estudios sobre los cineastas, como los de Collet $(1963,1972)$, Prédal $(1984,1991,1996)$ o Magny (1986, 1987, 1992, 1993), y sobre la concepción de la Nouvelle Vague como un movimiento conjunto, en trabajos como los de Marie (1997, 1999, 2012), Baecque (1998), Crisp (1993), Douchet (1998), Frondon (1995), o los españoles Riambau (2002) y Memba (2003).
} 
Por consiguiente, los cineastas del 68 encontraron su propia voz en la radicalización de los postulados de la Nouvelle Vague y, sobre todo, en la reivindicación del cine como espacio de la exploración formal al servicio de la forma misma y ya no del relato. Y fue en el discurso del yo que esta exploración tuvo su expresión más privilegiada. En su última parte, el mismo estudio sugería que, a diferencia de los filmes de la Nouvelle Vague, donde la visibilidad del Otro era todavía posible del mismo modo que la representación seguía siendo el punto de partida de los relatos, en la Post-Nouvelle Vague, en cambio, la representación ya no se pone en crisis a favor de la exploración figurativa, sino que los cineastas parten directamente de los problemas del lenguaje cinematográfico y de hallar soluciones en la dialéctica creada por el mismo lenguaje, situando al Otro en el espacio de lo ausente.

En suma, y todavía a modo de hipótesis, la asunción del rechazo y la resistencia del dolor que observamos en la generación del 68 apelan a una búsqueda ya no de la reflexión sobre lo visible, como lo hicieron sus predecesores, sino de la mirada y, más esencialmente, de su construcción. Los cineastas tomarían, por tanto, la separación del yo con el Otro, o lo que es lo mismo, del individuo con el mundo, como el principio fenomenológico de la construcción entre lo que es y lo que se muestra. Para ellos, el cine debería partir e instalarse en esta problemática. Pero si, paradójicamente, nos referimos a un cine que piensa la imagen a partir del cuerpo, ¿cómo dar voz a un cuerpo que se afirma desde los márgenes? ¿Cómo hacerlo partícipe de la imagen si afirmamos que el Otro ocupa lo ausente? He aquí las preguntas que, en nuestra opinión, se formulan los autores de la Post-Nouvelle Vague, ya no para poner en discusión qué es el cine, como lo hicieron los de la Nouvelle Vague heredando la pregunta formulada por André Bazin ${ }^{5}$, sino para llevar la discusión al hecho y ofrecer, por primera vez, el nacimiento de la imagen desde el lenguaje del cine. Pero, ¿por qué tomar el cuerpo y su separación?

\subsection{Gilles Deleuze: crisis sensoriomotor y cine de cuerpo}

De acuerdo con las tesis de Gilles Deleuze, el cine clásico (imagen-movimiento) se construye en base a una lógica sensoriomotora en la que el sentido de las imágenes responde a un encadenamiento de percepciones y acciones, a un sistema por tanto de causa-efecto. En el cine de la modernidad, Deleuze concibe un segundo tipo de imágenes (imagen-tiempo) en el que ya no existe una segunda imagen que ayude a producir sentido. Según el filósofo, la imagen-tiempo responde a una crisis del encadenamiento sensoriomotor, lo que provoca un viraje en el comportamiento del cuerpo y el cerebro, en tanto que materias sujetas a la lógica de encadenamiento motriz del cine clásico.

El reto del cine moderno sería, por tanto, producir el sentido de las imágenes desde el debilitamiento sensoriomotor y el déficit de acción. Deleuze observa este comportamiento en el neorrealismo italiano: en la situación real vivida por el personaje que supera la capacidad de desarrollar una acción en Roberto Rossellini, en la exploración del tedio y el vacío en Michelangelo Antonioni, o en la mezcla de

\footnotetext{
5 Nos referimos al título Qu'est-ce qu'est le cinéma? (trad. esp.: ¿Qué es el cine? (2008). Madrid: Rialp), que recoge los textos publicados por el crítico entre 1958 y 1962, y que fueron de gran influencia para la teoría y la praxis de los cineastas de la Nouvelle Vague.
} 
representaciones en el universo de Federico Fellini. El aflojamiento de los nexos motores lleva a actitudes de paseo, de vagabundeo, de sujetos errantes. El cuerpo toma protagonismo en el relato justamente por la carencia en la acción a desarrollar, lo que explicaría la paradoja que la falta de protagonismo en la acción y por tanto la marginalidad de los cuerpos implica una mayor atención a los mismos. Cuerpos que no son elementos partícipes de un espacio, pues eso sería someter el cuerpo a un comportamiento ajeno al mismo, sino que para crear un espacio y un tiempo desde los cuerpos sería necesario partir del "gestus", en el sentido de Brecht, y no de las actitudes.

Lo que llamamos gestus en general es el vínculo o el nudo de las actitudes entre sí, su coordinación recíproca pero en cuanto no depende de una historia previa, de una intriga preexistente o de una imagen-acción. Por el contrario, el gestus es el desarrollo de las actitudes mismas y, con este carácter, opera una teatralización directa de los cuerpos, a menudo muy discreta, pues se efectúa independientemente de cualquier rol. (Deleuze, 2004: 255).

Un cine basado en el gestus lo encontraríamos en los inicios de John Cassavetes, en Shadows (1959) o Faces (1968), donde "la historia debe ser segregada por los personajes", "el personaje se reduce a sus propias actitudes corporales, y que debe surgir de ellas es el gestus, es decir, un 'espectáculo', una teatralización o una dramatización que vale por cualquier intriga". Según Deleuze, la Nouvelle Vague aboga por este tipo de cine. François Truffaut, por ejemplo, a partir de las actitudes de Jean-Pierre Léaud, tan libres como conscientes de la ficción en la que participan, crea un modo de entender la dialéctica baziniana entre lo real y lo imaginario en el cine $^{6}$. Godard, por su lado, empieza a entender el espacio y el montaje en el cine a partir del teatro creado por los cuerpos, como tiene lugar entre los amantes de $L e$ mépris (1963) en el apartamento, o Nana (Anna Karina) en la habitación de Vivre sa vie (1962). En lo que concierne a Rivette, el cineasta de L'amour fou (1969) integra el teatro en el film, poniendo al actor entre el individuo y el actor, lo que genera un diálogo que plantea la permeabilidad entre distintos niveles de representación. Si la Nouvelle Vague llevó a explorar la praxis fílmica y su reflexión desde los cuerpos, "la post-Nouvelle Vague no cesará de trabajar y de inventar en estas direcciones", escribe Deleuze, mostrando que "el cine de los cuerpos no carece de peligros: una exaltación de los personajes marginales que hacen de sus vidas cotidianas una insípida ceremonia; un culto de la violencia gratuita en el encadenamiento de posturas; una cultura de actitudes catatónicas, histéricas o simplemente asilares" (Deleuze, 2004: 259-260).

Según el filósofo francés, los cuerpos de esta generación no están nunca en presente, sino que contienen el antes y el después, la espera y la fatiga. En este sentido, y a modo de síntesis, Domènec Font aclara que la Post-Nouvelle Vague parte de sus predecesores y de su relación con la experiencia cotidiana, con el espíritu moderno, la pareja y los avatares sentimentales, "pero frente a aquellos se sustraen a cualquier proyecto edificante sobre las tranches de vie a favor de un neorrealismo

\footnotetext{
${ }_{6}$ Para un análisis sobre cómo Jean-Pierre Léaud supuso una forma de teorizar el cine para Truffaut y una influencia entre los creadores a partir de la Nouvelle Vague, véase Vilaró, A. (2011). L'errància de l'actor després d'Antoine Doinel: sobre una tendència melancòlica en el cinema francès contemporani. Comunicació: Revista de Recerca i Anàlisi, 20 (1), pp. 19-40.
} 
de saturación, de un retrato más bien sombrío, en claroscuro, sobre la educación sentimental y la infelicidad. En sus películas se vive una impresión caótica, bien por la ausencia de una narración estructurada o por la sumisión del guión a los azares y psicodramas del rodaje" (Font, 2012: 431). La autobiografía sustituye la narración, siendo los cuerpos de los mismos cineastas partícipes de la búsqueda en el relato. Maurice Pialat, como demiurgo en À nos amours (1983) y Sous le soleil de Satan (1987); Jacques Doillon en La femme qui pleure (1979) y La fille de 15 ans (1989); o Chantal Akerman mostrándose a sí misma en sus primeros filmes: Saute ma ville (1968), La chambre (1972) o la ya mencionada Je tu il elle (1974). Y en este sentido, el caso de Garrel es el más singular.

\subsection{Philippe Garrel: el renacer de la imagen}

Ambos desplazamientos, de la acción a la fatiga del cuerpo y de la narración a la autobiografía, aparecen como principios imprescindibles en el universo de Philippe Garrel y, a su vez, explican la premisa planteada más arriba: entre las ambiciones de la Post-Nouvelle Vague estaba la de construir de nuevo la mirada. Porque para volver a dar existencia al cuerpo, para dotarlo de relación con el mundo, era necesario plantear la relación desde un nuevo gesto, y un gesto que Garrel piensa en términos de cine, esto es, haciendo que la condición de existencia del cuerpo dependa del ejercicio creado en el sí del plano y del montaje en particular.

Lo que importa en el cine de Garrel, como lo manifiesta Deleuze a partir del trabajo de Jean-Louis Schefer, ${ }^{7}$ no es "la presencia", que es patrimonio del teatro, sino la génesis de un "cuerpo desconocido", concretamente: un "comienzo de visible que no es todavía figura, que no es todavía una acción". El cine tiene que ser capaz de volver a darnos el mundo y el cuerpo a partir de la ausencia y para ello "es preciso que la cámara invente los movimientos o posiciones que corresponden a la génesis de los cuerpos y que sean el encadenamiento formal de sus posturas primordiales" (Deleuze, 2004: 267; 265-268). El plano conjunto y el travelín en La cicatrice intérieure, como el montaje en paralelo en Un ange passe (1975), la imagen inmóvil y silenciosa en Athanor (1972) y Le bleu des origines (1979), o la elipsis en Liberté, la nuit (1983): tal y como lo expone Nicole Brenez, nos encontramos frente a nuevos encadenamientos, nuevas posturas de cine, esto es, nuevas formas de montaje desde la presencia de los cuerpos (Brenez, 1998: 67-75; Casas, 2007: 73-79).

Esta exploración, propia de los primeros filmes de Garrel, tenía lugar en el cine experimental. Era necesario un cine radicalmente alejado de los cánones formales y del sistema de producción tradicional, para manifestar el malestar con la industria, con la convención, y hacer del cine el lugar de la expresión que piensa justamente esta inconformidad. El cine, según Garrel, se convierte de este modo en un refugio, pero no tanto para evitar el dolor y construir un mundo ajeno a éste, como para escuchar este dolor. El trabajo con la imagen deviene el ejercicio donde el grito de la rebelión puede expresarse libremente, también la experiencia de la droga o el pensamiento en el suicidio. Pero, tal y como se explica en L'enfant secret (1979), filme a medio camino entre la época experimental y la narrativa de Garrel, no serán

\footnotetext{
Schefer, J. L. (1980). L'homme ordinaire du cinéma. París: Cahiers du cinéma - Gallimard.
} 
los electrochoques los que harán que Garrel quiera seguir viviendo, sino la presencia de Christa Päffgen, más conocida como Nico. Cantante alemana en Velvet Underground y modelo de la Factory de Andy Warhol, Nico fue el gran amor del cineasta. Durante diez años Garrel encontró en ella no sólo una actriz, sino la poesía, la canción y el sentido del mismo cine. De un modo próximo al trabajo de Jean-Luc Godard con Anna Karina, Nico se convirtió en el único mundo a filmar por Garrel y más concretamente en la posibilidad del goce en el tormento. Pues como reconoce el cineasta, "filmar, como lo hice durante diez años a la mujer que amaba es algo bastante loco" (Garrel, Lescure, 1992: 89). La muerte de Nico en 1989 coincide con el abandono del cine experimental. Garrel necesita de la narración para llegar a la gente y explicar un relato que desde entonces sigue repitiéndose hasta en sus últimas cintas más célebres como La frontière de l'aube (2008) o La jalousie (2013): frente a la muerte de la mujer amada, un hijo nace con otra mujer, y este hijo guarda los ecos del amor de Nico, su música, y por tanto la posibilidad de ver todavía su rostro.

A pesar de la ruptura evidente entre ambos períodos, los une la misma ambición: en ambos períodos el cineasta configura una lógica de la relación entre las imágenes desde una alteridad en la que gobierna la falta del Otro. Para abordar esta discusión, las siguientes páginas se centran en el análisis estético -desde una aproximación descriptiva de las imágenes y de los recursos fílmicos utilizados- de dos filmes en particular: el que culmina con la primera etapa, La cicatrice intérieure (1972), y el que abre la segunda, Les baisers de secours (1989). La elección de ambos filmes responde a su interés autobiográfico y en particular al hecho de que el cineasta se sitúa frente a la cámara para evidenciar que la relación entre las imágenes tiene lugar en el vínculo entre su propia mirada y la mirada de los otros, de Nico y de Brigitte Sy respectivamente. De acuerdo con la hipótesis formulada anteriormente, de ambos filmes surge un pensamiento sobre la construcción de la mirada, esto es, de las imágenes, a partir de la relación entre los cuerpos.

\section{Filmar con el otro: el espacio-tiempo del amor en La cicatrice intérieure}

Las vidas de Nico y Philippe Garrel se cruzan cuando el cineasta acaba de rodar Le lit de la Vierge (1969). El director francés conoce a Nico como actriz en Chelsea Girls (Andy Warhol, 1966). Destaca una trilogía de los años en que Garrel y Nico crearon juntos: La cicatrice intérieure (1972), Athanor (1972) y Le berceau de cristal (1976). Sobre esta época explica el cineasta: "Mi intención era expresar el amor que tenía por ella. O quizás los filmes son el producto de este amor. No puedo considerarme, propiamente hablando, el autor de los filmes de la trilogía, pues ella fue verdaderamente realizada por los dos, 'dialogada' por ella, firmada por ella y por mí" (Garrel, Lescure, 1992: 64). Nico escribía los diálogos de La cicatrice intérieure. Garrel no sabía qué decía en ellos cuando la actriz hablaba en alemán, pero confiaba en sus palabras porque compartía el sentimiento de la misma separación con el mundo: "La dejaba hacer. Sabía que ella pensaba el mundo exactamente como yo lo pensaba" (Courant, 1983: 60). Se trataba de filmar con el otro para encontrar oxígeno en el universo compartido del amor, para hallar juntos el mismo deseo de salir de la crisis existencial que los invadía. 
Figura 1. El encuentro de Garrel y Nico.

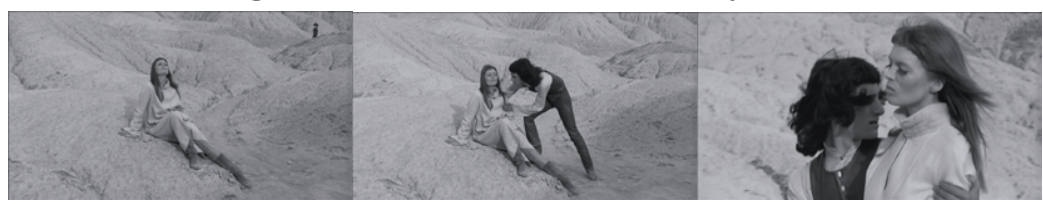

Figura 2. El travelín circular de La cicatrice intérieure, espacio-tiempo del amor loco.
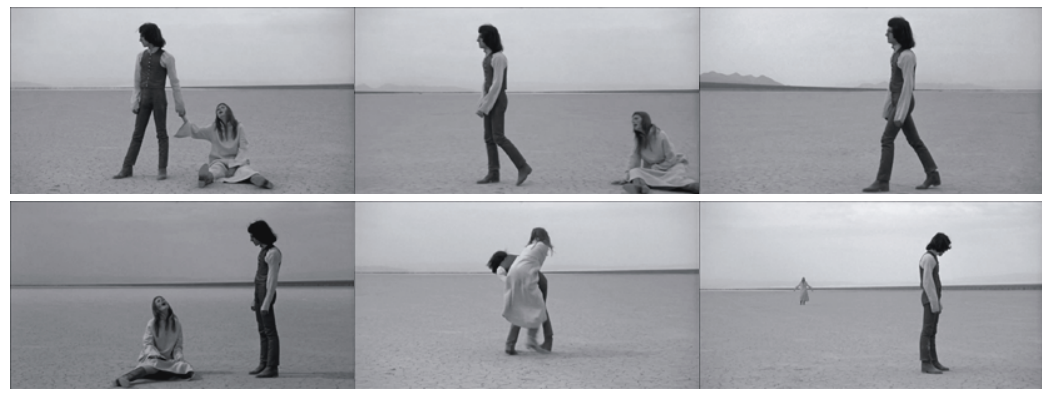

Figura 3. La caída de los cuerpos después del amor loco.

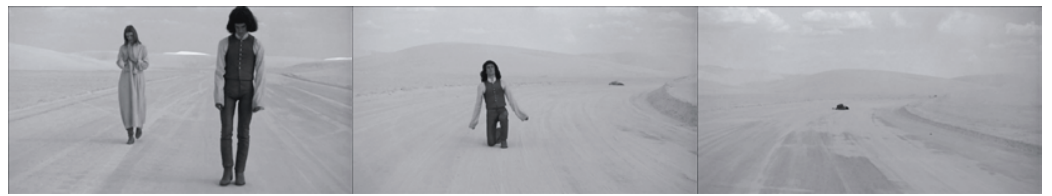

El travelín circular de La cicatrice intérieure es la metáfora más exacta de este sentimiento. El film arranca con Nico sentada en una roca del desierto, con los ojos cerrados, inmóvil. Philippe Garrel la coge de la mano. “¿Adónde me llevas?”, pregunta ella, mientras él sigue mirando atrás, temerario del rapto y buscando a su vez un lugar para no ser descubierto, para esconderse con ella, para encontrar el cobijo del amor (fig. 1). Un fundido a negro conecta con la secuencia del travelín. Nico y Garrel ocupan el centro de la imagen: él, en pie, mira a su derecha, fuera de campo; ella llora, abandonada al suelo. "Philippe, no puedo soñar. ¿Puedes ayudarme?". Garrel desaparece mientras escuchamos la voz de Nico entonando Janitor of Lunacy, un canto dirigido al guardián de la locura para que identifique su destino, pero para que no la deje avanzar más y pueda vivir en el sueño. Las palabras de la canción de Nico resuenan en el cuerpo de Garrel, que camina trazando una circunferencia, seguido por el movimiento de cámara (fig. 2). Garrel vuelve al punto de partida dos veces, manifestando el deseo de escapar, de abandonar su proyecto, y a su vez la imposibilidad de realizarlo, o la necesidad de permanecer en el mismo lugar. El sentimiento de cada cuerpo por sí mismo se convierte de este modo en el sentimiento compartido por los amantes, un sentimiento fundado sin embargo en una diferencia en su relación: mientras que Garrel hubiera deseado crear el escenario del amor incluyendo Nico en su círculo, ella pide no ser absorbida por el universo del cineasta. "No te necesito", le dice ella, alejándose antes de ser convertida en una imagen a los ojos del héroe. 
La relación que se plantea aquí entre la separación y unión de los cuerpos resuena, en primer lugar, en el espacio que construye el mismo movimiento de cámara, situando la imaginación y la realidad en un mismo plano. He aquí el reto y la riqueza ontológica del cine, la imbricada dialéctica con la que André Bazin definió el necesario flujo y reflujo entre la realidad y la imaginación ${ }^{8}$. Sueño y fenómeno se hallan separados por la línea del horizonte que divide el cielo y la tierra en el paisaje que ocupan Nico y Garrel. El espectador asiste al espacio que da nombre al filme: la cicatriz interior de los cuerpos, un corte inmenso en un desierto sin profundidad de campo, donde el movimiento es de observación, abierto al infinito, pero cerrado a su vez, ya que la circularidad delimita el espacio. Ni siquiera los dos giros de $360^{\circ}$ del travelín sobre la misma imagen encontrarían la ósmosis perfecta de esa división, pero tampoco la separación definitiva, pues el plano secuencia no permite eludir al plano conjunto, lo que supone que, en segundo lugar, no se trate sólo de una relación espacial, sino también de tiempo. Pues la ambición del travelín es poder unir el yo y el otro en un mismo tiempo. El plano secuencia transporta a un "no-lugar", pero también, como lo observó Sergi Sánchez, a un "no-tiempo". Porque el mismo cierre sobre la imagen, que se encarga de borrar cualquier otro espacio, en tanto que delimitación, permite que la acción no avance. Estamos frente a la matriz donde el cuerpo todavía tiene que nacer, frente al abismo de los orígenes, la Gola primigenia según los mitos presentada por Garrel en forma de polvo blanco (Casas, 2007: 65-71).

Es por esta crisis y reconstrucción del espacio-tiempo que comprendemos la aseveración del cineasta: "Este travelín es un plano secuencia en estado puro, una suerte de grado cero del plano secuencia" (Garrel, Lescure, 1992: 64). Si con "grado cero de plano secuencia" Garrel designaba la voluntad de empezar de nuevo, hacía falta llevar el lugar a un "no-lugar" y el tiempo a un "no-tiempo". Pero para empezar de un modo distinto. Como decíamos más arriba, el proyecto de Garrel fue la búsqueda de la relación con el mundo desde la relación que permite establecer el cine con los elementos que participan de la imagen y con los cuerpos en particular. De este modo la imagen en el cine debería plantear soluciones, o abrir nuevos interrogantes a aquello que los cuerpos por sí solos son incapaces de pensar. La secuencia del travelín circular (figura 2) no casualmente se dispone entre dos secuencias que abogan precisamente por dotar la cámara de poder y autonomía frente a los cuerpos. Si en el primer caso (figura 1), el movimiento de la cámara sigue la trayectoria de Garrel en el gesto de recoger a Nico, en la secuencia posterior al travelín (figura 3), en cambio, el movimiento ya no depende de la trayectoria de los cuerpos; estos caen, separados, y dejan de moverse, la cámara los abandona y sigue su trayecto, mostrando los cuerpos, minúsculos, al fondo de la imagen. En resumen, poniendo los cuerpos en crisis, Garrel invita al espectador a desaprender la convención según la cual la acción nace con el personaje y poder explicar que en el cine la escritura nace de la relación que la cámara establece con la imagen.

\footnotetext{
8 "Lo que importa es que la materia prima del film es auténtica y a la vez, y sin embargo, 'aquello es cine'. Entonces la pantalla reproduce el flujo y el reflujo de nuestra imaginación que se alimenta de la realidad, sustituyéndola; la fábula nace de la experiencia que la imaginación trasciende. Pero, recíprocamente, hace falta que lo imaginario tenga sobre la pantalla la densidad espacial de lo real" (Bazin, 2008: 74).
} 
La cicatrice intérieure nos sitúa frente a un locus de los orígenes, de la materia prima -el Humus de la Tierra, escribió Henri Langlois-, de aquella materia de la que el hombre se habría separado y que, para Garrel, sólo el amor y el íntimo vínculo con el Otro podía hacer revivir. Pues de forma análoga a Dante cuando escribió a partir del rostro de Beatriz, el amor de Nico y Garrel ocupa el más allá como un presente eterno, atemporal a los ojos de Dios, y sin embargo creado desde su fisicidad. Es conocido el estudio de Erich Auerbach al respeto: "Para Dante la Beatriz terrenal es, desde el primer día de su aparición, un milagro enviado del cielo, una encarnación de la verdad divina. [...] Pero una encarnación y un milagro son cosas realmente sucedidas; los milagros sólo suceden en la tierra y la encarnación es carne. (1998: 127)"'. Según el crítico alemán, Beatriz fue para Dante una figura y no una alegoría, esto es, la encarnación de la revelación. Esta fue también la ambición de Garrel con Nico y de este modo lo explica Brenez: "Nico encarna el ídolo primitivo, el que propicia las declinaciones figurativas, [...] la encarnación moderna de los misterios de la creación y de la muerte. [...] Basta filmar a Nico, la contemplación del rostro liso e impenetrable del ídolo encarna todas las fábulas y libera mucho más que todos los cuentos" (Casas, 2004: 74).

Tras la caída de los cuerpos y la construcción del espacio de los orígenes como el locus amoenus del amor, el filme emprende un viaje que remite a la búsqueda del Grial: la llegada del arquero sobre la Tierra, el control del agua, el ritual del fuego. Garrel presenta el descubrimiento del mundo como el descubrimiento de la imagen, la música y la palabra; propone redescubrir el cine a través de las formas de lo elemental. Como la nueva imagen tiene que emerger desde un nivel cero, será la presencia de un niño quien protagonizará la aventura de esta búsqueda: el niño asume el movimiento libre de la cámara, sigue la continuidad del amor de los amantes que, conocedores del mundo, son esclavos de sus propias actitudes.

\section{Filmar desde el otro: la substitución del Otro y la significancia del rostro}

"Después de este travelín, que fue el último que concebí... iy el más complicado!, dejé de ser inventivo en mis figuras". Garrel es consciente del giro de su obra después de la muerte de Nico: "Ahora me doy cuenta que es mejor preocuparse de explicar una historia que de ocuparse de la cámara, que es algo aleatorio" (Courant, 1983: 59). Como ya anunciamos, esta historia es siempre la misma: el nacimiento

\footnotetext{
9 Sobre la revelación encarnada de Beatriz escribe Auerbach: "Sentimos la aroma de su persona humana, que era joven, admirablemente bella, que sentía dolor y que murió; asistimos a su arrobamiento, y en la transfiguración hacia el más allá se mantiene y se potencia su figura humana, su contingencia. Por ello, la Vita nuova no es sólo una obra de juventud poco original y descompensada, tal como sostienen algunos hoy en día; no se pueden negar sus ambigüedades, ciertamente, e innegable es también su génesis a partir de una superación violenta del estilo de la época; pero la necesidad de tal superación tenía su origen en la esencia cristiana del tema, de la inclusión consciente de la incertidumbre y de la inseguridad terrenales dentro de la perfección; ambigüedades de un origen semejante se encuentran en cada creación mimética auténticamente cristiana, especialmente en los libros del Nuevo Testamento. Pues lo que Dante fue y es, el poeta cristiano de la realidad terrenal mantenida en el más allá, en la perfección debida al juicio divino, llegó a serlo en su vivencia de juventud, y la Vita nuova es el testimonio de este devenir". (Auerbach, 2008: 107).
} 
del hijo informa de la supervivencia a la ruptura o del gran amor que ya no existe. En Les baisers de secours (1989) asistimos al film más abiertamente autobiográfico del director francés, un documento donde se muestra el propio cineasta junto a su mujer, Brigitte Sy, su hijo Louis Garrel y su padre Maurice Garrel. Este último plantea una reflexión a Philippe alrededor del hijo como substitución del tiempo del amor:

A veces hay momentos de amor entre un hombre y una mujer que no podemos creer que sean momentos propios del tiempo, momentos como los otros, que son hechos para pasar y desaparecer. [...] Entonces tenemos un hijo, pero no para el hijo, sino para el amor, para poder guardar todos estos momentos, $\mathrm{y}$ tenemos el sentimiento que el hijo es la encarnación de este amor.

Figura que mantiene la salvación del amor, el hijo -el mismo Louis Garrel que de adulto asumirá el rol y las mismas historias del padre en Les amants réguliers (2005) o La frontière de l'aube (2008)- posibilita no tanto la continuidad del yo, sino el espacio-tiempo de un sentimiento que no tiene representación en el espacio-tiempo de la vida y que Garrel quiso mostrar en sus años de creación con Nico. Sin embargo, el tema central de Les baisers de secours es otro: el de la madre, que no encarna la idea del amour fou de Nico, pero sí la idea del Otro, del cuerpo que mantiene la relación y por tanto la necesidad de hacer cine. Si con Nico no existía el creador, sólo dos cuerpos frente a la pantalla, unidos por la confianza del Otro que ve el mundo con los mismos ojos, ¿cómo reencontrar el plano conjunto en el espacio de la Tierra, si el tiempo de la creación fue concebido en un terreno del más allá, atemporal y eterno?

Dedicado a Nico después de su muerte, J'entends plus la guitare (1991) explica esta situación: Gérard (Benoît Régent), que encarna a Philippe Garrel, ha tenido un hijo con Aline, interpretada por la misma mujer del cineasta, Brigitte Sy. En un momento dado aparece Marianne (Johanna ter Steege) ${ }^{10}$, que interpreta el rol de Nico. Aline decide quedar a solas con ella. La nueva mujer del director quiere saber cómo fue el amor que vivió, quiere conocer el rostro que ahora ella substituye y que sin embargo nunca podrá ser. "Quizás no fue muy feliz conmigo, pero era otra época". “QQué quieres decir?”. “Quizás no necesitábamos ser felices. Quizás no era esto lo que buscábamos en todo caso”. “QQué era entonces?”. "Ser héroes. Cambiar la vida quizás". Si Gérard ahora está con Aline es para ser feliz y no para volver a ser un héroe. Pese a conocer el pasado, Aline no cambiará nada. "No podemos hacer nada contra el pasado", recuerda Marianne. Tras la conversación entre ambas, Aline desaparece, asumiendo la figura de la mujer regular, débil, intercambiable; así lo expresa ella misma a Gérard al final del film. Pero, ¿qué es hoy Marianne? Cuando Aline desaparece de la conversación (fig. 4) un breve contraplano es suficiente para ver al rostro de Marianne cubierto de lágrimas, mientras sentimos la guitarra y las olas del mar del inicio del film, cuando la droga todavía no había destruido su amor. Dos mujeres lloran, ocupantes de un avenir que mira a un pasado insalvable. Marianne llora por la muerte que tendrá que afrontar sola, llora porque con ella Garrel no consumó el proyecto del hijo. Aline llora porque ocupa un avenir que mira hacia un pasado irrecuperable. El reto de Aline/Sy consistirá en luchar contra este pasado, con el contraplano de la imagen de Nico, que se impone en el presente de Garrel.

\footnotetext{
${ }^{10}$ En dos films inmediatamente posteriores de Garrel, La naissance de l'amour (1993) y Cour fantôme (1996), la misma actriz (Johanna ter Steege) interpreta el mismo rol inspirado en el amor pasado e irrecuperable de Nico.
} 
Figura 4. El contraplano ausente, el llanto de Nico/Marianne.
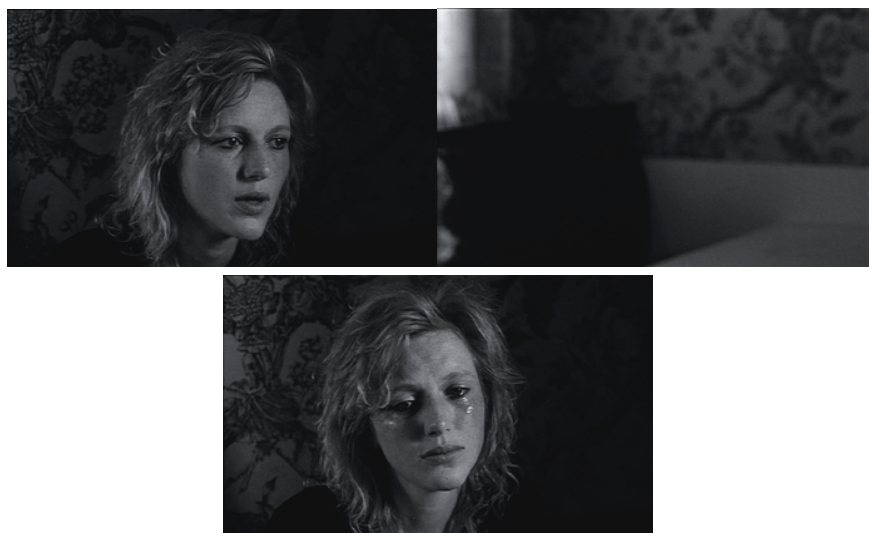

Figura 5. El Otro como responsable de la mirada en Les baisers de secours.

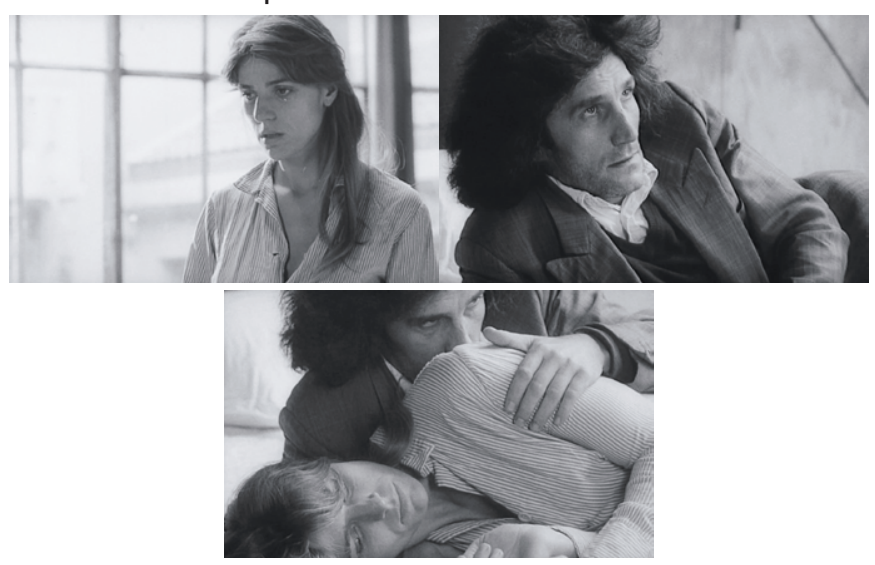

Les baisers de secours plantea este reto. Explica Garrel que después de Elle a passé tant d'heures sous les Sunlights (1985) Brigitte Sy manifestó cierta tristeza porque no le confió el rol que de ella encarna Mireille Perrier en el film. En Les baisers de secours, Mathieu (Philippe Garrel) le asigna un rol importante: el de una mujer (Jeanne) que se ve sustituida en un film que habla de su vida. La película arranca alrededor de esta discusión: "Es tu papel, no eres tú”, le dice Garrel. “¿Cuál es la diferencia?", responde ella. "No lo sé todavía”. Para Garrel/Mathieu, si existe una solución, ésta todavía no tiene nombre y es ella quien tiene que discernirla. He aquí el problema: él la quiere ver, pero no quiere verse él mismo. "¿No quieres vernos a los dos? ¿No quieres verme en relación contigo? ¿Tienes miedo de vernos juntos?”. Ni una imagen de conjunto en el espejo, ni un contraplano. Que Mathieu se mantenga al margen, fuera de campo, es para Jeanne la demostración de que no la ama. "Tú quieres verme a mí o a ti. Sin embargo, amar no es verse cuando vemos al otro, sino ver al otro al mismo tiempo que nos vemos". Si en La cicatrice intérieure era imprescindible el trabajo con el otro, el mismo trabajo es ahora un imposible: Garrel 
plantea la imposibilidad de asumir desde la mirada el plano conjunto, la carencia, por tanto, del trabajo con el otro.

"Quieres mostrar cómo me amas, pero no cómo eres amado". La constatación de Brigitte supone un giro en la escena y es precisamente el giro que indica un cambio en la obra de Garrel: el trabajo con el otro, en el espacio-tiempo cotidiano, fuera por tanto del espacio-tiempo del amour fou, tiene que llegar del Otro, concediendo al Otro la responsabilidad de la mirada y por tanto de la lógica de las imágenes. (fig. 5) Ella contribuye a que el plano secuencia se rompa para mostrar el contraplano del que mira, para decirle que el que mira debe aprender a decir ya no un "te quiero", sino un "me amas", sin formularlo como pregunta, sino como un hecho. El corte en la imagen es necesario para reconocer la existencia de cada ser y poder entonces crear el plano conjunto. Es decir, para hallar el sentimiento compartido es necesario que no sea el cineasta quien hace significante el rostro del Otro, sino que éste es significante a priori. Dicho de otro modo: Garrel vio necesario partir de la responsabilidad del Otro, de su diferencia, de la resistencia a ser absorbido por un discurso propio del Yo.

\section{La cuestión de la relación en el cine. A modo de conclusión}

"Lo infinito no se presenta a un pensamiento trascendental, ni siquiera a la actividad consentida, sino en el Otro: él se encarga conmigo y me pone en cuestión y me obliga por su esencia de infinito. Este 'algo' que se llama significación surge en el ser con el lenguaje, porque la esencia del lenguaje es la relación con el otro" (Lévinas, 2012: 231). La mirada de Garrel en Les baisers de secours sugiere, de acuerdo con la fenomenología de Emmanuel Lévinas, que sea el Otro, por su presencia y su significancia, quien determine el discurso y, por consiguiente, la mirada. No por la insuficiencia del Yo, sino por la condición de infinito que debe tener el Otro antes de cualquier relación. Las tesis de Lévinas llevarían a pensar la lógica del montaje desde una relación ética y no desde una relación sensoriomotora, aproximación que tendría que ser explorada más profundamente en otro estudio desde la raíz fenomenológica a partir de la cual Deleuze piensa la crisis de la imagen-movimiento y la desconexión del

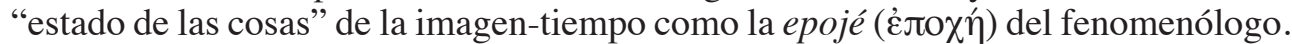

Para abordar la relación respetuosa de la alteridad, Lévinas concibe como necesaria la separación entre el Yo y el Otro. Porque "lo que me permito exigir a mí mismo no es comparable a lo que estoy en mi derecho a exigir del Otro", o más profundamente, porque "sin separación no habría habido verdad: sólo habría habido ser”, (Lévinas, 2012: 51, 60). Como vimos, la motivación de Garrel por el cine vino precisamente por hablar de un sentimiento de separación. Un sentimiento que el cineasta compartió con Nico en su relación con el mundo, pero que, como lo sugiere Lévinas, se vuelve necesaria cuando lo que se plantea es la relación con el más próximo. En Les baisers de secours seguimos en la misma figura de la cicatriz interior, y si ahora Brigitte dice "tómame" no es para buscar un cambio en la mirada, en relación con el "no te necesito" de Nico. La afirmación de Brigitte existe para que Garrel no olvide que él es también partícipe de la mirada, y que la mirada responde a un cruce y no a una única dirección. Que él también es mirado, y que es mirado antes de que él empiece a desear -de donde surge la necesidad de coger la cámara para mostrar o 
representar-. Brigitte existe para enseñar a Garrel el contraplano que de la imagen él también ocupa, para recordarle que pensó el amor con el otro, esto es, desde el otro y no sólo hacia el otro. Existe para hacerle ver la necesidad de entender la significancia de los cuerpos si quiere volver a dar sentido al amor, o lo que es lo mismo, al uso de las imágenes: hacer del plano/contraplano una figura necesaria, exigida por los cuerpos, de la misma manera que lo era el travelín en La cicatrice intérieure.

En suma, Philippe Garrel se convierte en el cineasta que culmina con el proyecto sobre la alteridad planteado por los autores de la Nouvelle Vague, llevando los principios comunes de la Post-Nouvelle Vague -la fatiga del cuerpo y el relato autobiográfico- al centro de una exploración figurativa y de la relación con la imagen, arrancando su trabajo en la conciencia de la separación del individuo con el mundo. Tomar conciencia de la separación supondría integrar varias miradas en un plano, para rechazar el silencio de la soledad -del creador con la obra, pero también del individuo con el mundo- y poner en una misma imagen la realidad y el fuera de campo, el espacio-tiempo de la experiencia y el fantasma atemporal y eterno, lo real y lo imaginario. Tomar conciencia de la separación lleva por tanto a cuestionar la ontología del filme, mientras, a su vez, para realizarlo Garrel entiende que es necesario ser partícipe de ello, ser objeto del proceso figurativo, esto es, someter el cuerpo del creador a la lógica de las imágenes, pensando la apertura de las imágenes desde la apertura de los cuerpos. Tomar conciencia de la separación supondría, en definitiva, entregar la posibilidad de mirar al otro cuerpo -Nico, Brigitte, pero también Louis o Maurice-, para poder entrar de este modo en diálogo con otra imagen posible, presente o ausente, dentro o fuera de campo, pero necesaria para sobrevivir.

Pensar el montaje en estos términos permite cuestionar el cine no sólo más allá de la representación, como lo exploró el cine clásico, sino también más allá de la reflexión sobre lo visible, como lo hicieron los primeros cineastas de la modernidad, y entre ellos, el gran admirado de Garrel, Jean-Luc Godard. "Lo que crean los filmes son problemas de imagen" (Aumont, 1996: 150). Los dos períodos de Garrel ponen de manifiesto que el cine responde a la problematización de la imagen y que ésta llega por medio de la relación: tanto para hallar una escritura entre la cámara y los cuerpos como para pensar la mirada. Porque, ¿qué otro arte expresa mejor que el cine la cuestión de la relación y por tanto, del vínculo entre el hombre y el mundo? Robert Bresson fue el primer cineasta en plantearlo, y desde la teoría del film, Nicole Brenez fue muy clara en este sentido: "El cine representa una investigación de conjunto sobre el vínculo y la relación. En el cine, todo se encuentra sujeto a una circulación" (Brenez, 1998: 12). De la exploración del lenguaje de la cámara al pensamiento de la mirada a partir del Otro, de la inquietud figurativa a la cuestión ética de las imágenes. La filmografía de Garrel se erige de este modo como una de las investigaciones sobre la relación. 


\section{Referencias bibliográficas}

AUERBACH, E. (2008). Dante, poeta del mundo terrenal. Barcelona: Acantilado. AUERBACH, E. (1998). Figura. Madrid: Trotta.

AUMONT, J. (1996). À quoi pensent les films? París: Séguier.

BAECQUE,A. (1998). La nouvelle vague. Portrait d'une jeunesse. Paris: Flammarion. BAZIN, A. (2008). ¿Qué es el cine? Madrid: Rialp.

BRENEZ, N. (1998). De la figure en général et du corps en particulier. L’invention figurative au cinéma. París, DeBoeck Université.

BRENEZ, N. (2007) "Filmar, como yo lo he hecho durante diez años, a una mujer a la que uno quiere es en sí algo bastante loco...". Sistema simbólico y giro narrativo en la obra de Philippe Garrel. En Q. Casas (coord.). Philippe Garrel: El cine revelado. (pp. 73-79). San Sebastián: Festival Internacional de Cine de San Sebastián.

BRESSON, R. (1988). Notes sur le cinématographe. París: Gallimard.

COLLET, J. (1963). Jean-Luc Godard. París: Seghers.

COLlET, J. (1972). Le Cinéma en question: Rozier, Chabrol, Rivette, Truffaut, Demy, Rohmer. París: Lherminier.

COURANT, G. (1983). Philippe Garrel. Entretiens. París: Studio 43.

CRISP, C. (1993). Classic French Cinema (1930-1960). Bloomington: Indiana University Press.

DANEY, S. (1996). La rampe. Cahier critique 1970-1982. París: Cahiers du cinéma - Gallimard.

DELEUZE, G. (2004). La imagen-tiempo. Estudios sobre cine 2. Barcelona: Paidós. FONT, D. (2012). Cuerpo a cuerpo. Radiografías del cine contemporáneo. Barcelona: Galaxia Gutenberg - Círculo de Lectores.

FRONDON, J-M. (1995). L’Âge moderne du cinéma français. De la Nouvelle Vague à nos jours. París: Flammarion.

GARREL, P.; LESCURE, T. (1992). Une caméra à la place du cour. Provence Alpes Côte d'Azur: Admiranda/Institut de l'Image.

LALANNE, J-M. (2002). Le cinéma français, modèle esthétique. Cahiers du ciné$m a, 568,80-81$.

LÉVINAS, E. (2012). Totalidad e infinito. Ensayo sobre la exterioridad. Salamanca: Sígueme.

MAGNY, J. (1986). Eric Rohmer. París: Rivages-Cinéma.

MAGNY, J. (1987). Claude Chabrol. París: Cahiers du Cinéma/L'Étoile.

MAGNY, J. et al. (1992). Marguerite Duras: el cine del desgarro. València: Ediciones de la Mirada.

MAGNY, J. et al. (1993). Maurice Pialat. París: Cahiers du Cinéma.

MARIE, M. (1997). La Nouvelle Vague. París: Nathan.

MARIE, M. (comp.) (1999). El nuevo cine francés. València/Gijón: Filmoteca de la Generalitat/Festival de Cine de Gijón.

MARIE, M. (2012). La Nouvelle Vague. Una escuela artística. Madrid: Alianza.

MEMBA, J. (2003). La Nouvelle Vague. Madrid: T\&B.

PAÏNI, D. (dir.) (1988). Philippe Garrel. Ville de Pantin: Studio 43.

PHILIPPON, A. (1986). Jean Eustache. París: Cahiers du cinéma.

PRÉDAL, R. (1984). Le Cinéma français contemporain. París: Cerf. 
PRÉDAL, R. (1991). Le Cinéma français depuis 1945. París: Nathan.

PRÉDAL, R. (1996). 50 Ans de cinéma français. París: Nathan.

RIAMBAU, E. (2002). El cine francés: 1958-1998. De la Nouvelle Vague al final de la escapada. Barcelona: Paidós.

SÁNCHEZ, S. (2007). No aquí. No ahora. De La cicatrice intérieure y una cierta tendencia en el cine contemporáneo. En Q. Casas (coord.). Philippe Garrel: El cine revelado. (pp. 65-71). San Sebastián: Festival Internacional de Cine de San Sebastián.

VILARÓ, A. (2011). L'errància de l'actor després d'Antoine Doinel. Sobre una tendència melancòlica en el cinema francès contemporani. Comunicació. Revista de Recerca i d'Anàlisi, 28(1), 19-40.

SÁNCHEZ, S. (2016). Entre la representación y la figuración. El cine de la Nouvelle Vague: una revisión histórica. Historia y comunicación social, 21(1), 221-239. 